\title{
Effectiveness of low-level laser therapy for patients with carpal tunnel syndrome: design of a randomized single-blinded controlled trial
}

\author{
Rafael Inácio Barbosa ${ }^{1 *}$, Eula Katucha da Silva Rodrigues ${ }^{1}$, Guilherme Tamanini ${ }^{1}$, Alexandre Márcio Marcolino ${ }^{1}$, \\ Valéria Meirelles Carril Elui ${ }^{2}$, Rinaldo Roberto de Jesus Guirro ${ }^{3}$, Nilton Mazzer ${ }^{3}$ and \\ Marisa de Cássia Registro Fonseca ${ }^{3}$
}

\begin{abstract}
Background: Carpal tunnel syndrome is the most common neuropathy in the upper extremity, resulting from the compression of the median nerve at wrist level. Clinical studies are essentials to present evidence on therapeutic resources use at early restoration on peripheral nerve functionality. Low-level laser therapy has been widely investigated in researches related to nerve regeneration. Therefore, it is suggested that the effect of low-level laser therapy associated with other conservative rehabilitation techniques may positively affect symptoms and overall hand function in compressive neuropathies such as carpal tunnel syndrome. The aim of this study is to evaluate the effectiveness of low-level laser therapy in addition to orthoses therapy and home orientations in patients with carpal tunnel syndrome.

Methods/Design: Patients older than 18 years old will be included, with clinical diagnosis of carpal tunnel syndrome, excluding comorbidies. A physiotherapist will conduct intervention, with a blinding evaluator. Randomization will be applied to allocate the patients in each group: with association or not to low-level laser therapy. All of them will be submitted to orthoses therapy and home orientations. Outcome will be assessed through: pain visual analogic scale, Semmes Weinstein monofilaments ${ }^{\mathrm{TM}}$ threshold sensibility test, Pinch Gauge ${ }^{\mathrm{TM}}$, Boston Carpal Tunnel Questionnaire and two point discrimination test.
\end{abstract}

Discussion: This paper describes the design of a randomized controlled trial, which aim to assess the effectiveness of conservative treatment added to low-level laser therapy for patients with carpal tunnel syndrome.

Trial registration: Brazilian Clinical Trials Registry (ReBec) - 75ddtf / Universal Trial Number: U1111-1121-5184

Keywords: Carpal tunnel syndrome, Low-level laser therapy, Rehabilitation

\section{Background}

Carpal tunnel syndrome (CTS) is the most common neuropathy in the upper extremity, resulting from the compression of the median nerve at wrist level. The compression is related with increased pressure at the carpal tunnel, elicited by the expansion of the structures contained within. Inflammatory or hemorrhagic conditions affecting the wrist, polyneuropathies, diabetes, rheumatoid

\footnotetext{
* Correspondence: ribarbosa@hcrp.usp.br

'Rehabilitation and Functional Performance Program, Faculty of Medicine of Ribeirão Preto, University of São Paulo, Avenida Bandeirantes, 3900, Ribeirão Preto, SP CEP 14049-900, Brasil

Full list of author information is available at the end of the article
}

arthritis, hypothyroidism, pregnancy and other hormonal alterations are also related with CTS [1-3].

The diagnosis of CTS is based on patient history and specific physical examination, and confirmed by complementary exams such as electroneuromyography. It affects mostly women in their fourth to seventh decade, presenting painful numbness at the median nerve path, often relieved with shaking the hands repeatedly (Flick's sign) $[4,5]$.

In order to properly assess the relief of symptoms and functional outcomes after conservative or surgical treatment of CTS, health professionals search for evaluation methods that are valid and reliable. Objective and

\section{Biomed Central}


subjective parameters must be taken into account, like measurements of pain, grip and pinch strength, sensory assessment, dexterity and patient perceived outcomes, through self-reported measures like the Boston Carpal Tunnel Questionnaire (BCTQ) [6]. The association of objective and subjective measures provides a better understanding about the physical and functional impact of CTS $[7,8]$.

There are numerous instruments for sensory evaluation of the hand described in the literature [9-13]. Of all methods available, two point discrimination (2PD) and assessment of touch thresholds with Semmes Weinstein Monofilaments are most widely used in patients with CTS [9].

Pinch strength can be accessed through a dynamometer, such as the Pinch Gauge ${ }^{\mathrm{TM}}$. Patients with CTS usually present diminished pinch strength, mostly in severe cases. The assessment of pinch strength can also help with determination of CTS severity degrees [14]. Amongst the available pinches to be assessed, pulp-topulp pinch seems to be the most responsive for CTS patients, due to the fact that is performed by muscles innervated by the median nerve [15].

The conservative treatment of CTS is based on nonsteroidal anti-inflammatory drugs, local steroid injections and wrist splinting [16]. Other modalities like exercise therapy, therapeutic ultrasound and low level laser therapy are also described in the literature, being commonly used for the conservative treatment of CTS [17].

Patient education, with orientations about body posture while performing different activities of daily living are an important part of the rehabilitation program for conservative treatment of CTS. The patient must avoid repetitive wrist movements; especially wrist flexion associated with prolonged grip activities. Patient education booklets have showed great efficacy as a complement of treatment in many upper limb disorders [18].

Different types of wrist orthoses with variations in immobilization angles are reported in the literature as effective for CTS treatment. Orthoses is the most widely used method of conservative treatment, and its effectiveness is based on the principle that adequate positioning the wrist minimizes the compression of the median nerve, maintaining an optimal position to preserving the volume of the carpal tunnel and providing rest to the structures that go through the wrist, thus relieving the symptoms of CTS. The orthoses should be worn at night, although for patients with severe symptoms it can be also used during the day (full time or intermittent). In certain cases a orthoses that also immobilizes the metacarpophalangeal joints with 20 to 40 degrees of flexion can be prescribed, in order to minimize painful symptoms due to lumbrical muscles hypertrophy that contributes to the increased pressure at the carpal tunnel [19].

Among the available resources, studies with low level laser therapy (LLLT) demonstrated effectiveness for conservative treatment of CTS, probably due to LLLT biophysical effect in neural tissue that can facilitate its regeneration [20].

Some studies have focused on LLLT application in peripheral nerve injuries in the last decades. The first report of LLLT use with this purpose dates from the late 70's by Rochkind et al., and since the early 80 's the scientific interest in this subject has increased, with papers demonstrating positive effects of LLLT in nerve cells regeneration [21,22]. From this moment on, other experimental studies were conducted in order to understand the role of that therapeutic modality in peripheral nerve regrowth and functional rehabilitation after nerve injuries [23-28]. Therefore, it is suggested that the effect of LLLT associated with other conservative rehabilitation techniques may positively affect symptoms and overall hand function in compressive neuropathies such as CTS.

\section{Methods/Design}

The trial is a prospective randomized clinical trial, adhered to CONSORT guidelines, with the objective of assessing the effectiveness of conservative treatment with LLLT for patients with CTS, associated or not with other modalities like wrist orthoses and a patient education booklet.

\section{Ethics}

The present study was approved by the Ethics Committee at the Hospital Clinics Faculty of Medicine of Ribeirão Preto (process number 7107/2010). All subjects recruited will sign an informed consent form.

\section{Eligibility criteria}

Eligibility criteria are age over 18 years, clinical diagnosis of CTS, with no history or current associated upper limb injuries due to orthopedic, neurologic or rheumatologic disorders (Figure 1).

\section{Recruitment}

Sixty patients with clinical and Electroneuromyography (EMG) diagnosis of CTS referred from a University Hospital will be recruited for our study. After an initial assessment, all patients that fit the inclusion criteria will be randomized to two different groups through a computer-generated list unknown to the recruiters, as follows:

- Control group. Conservative treatment with night splinting and patient education for 6 weeks. 


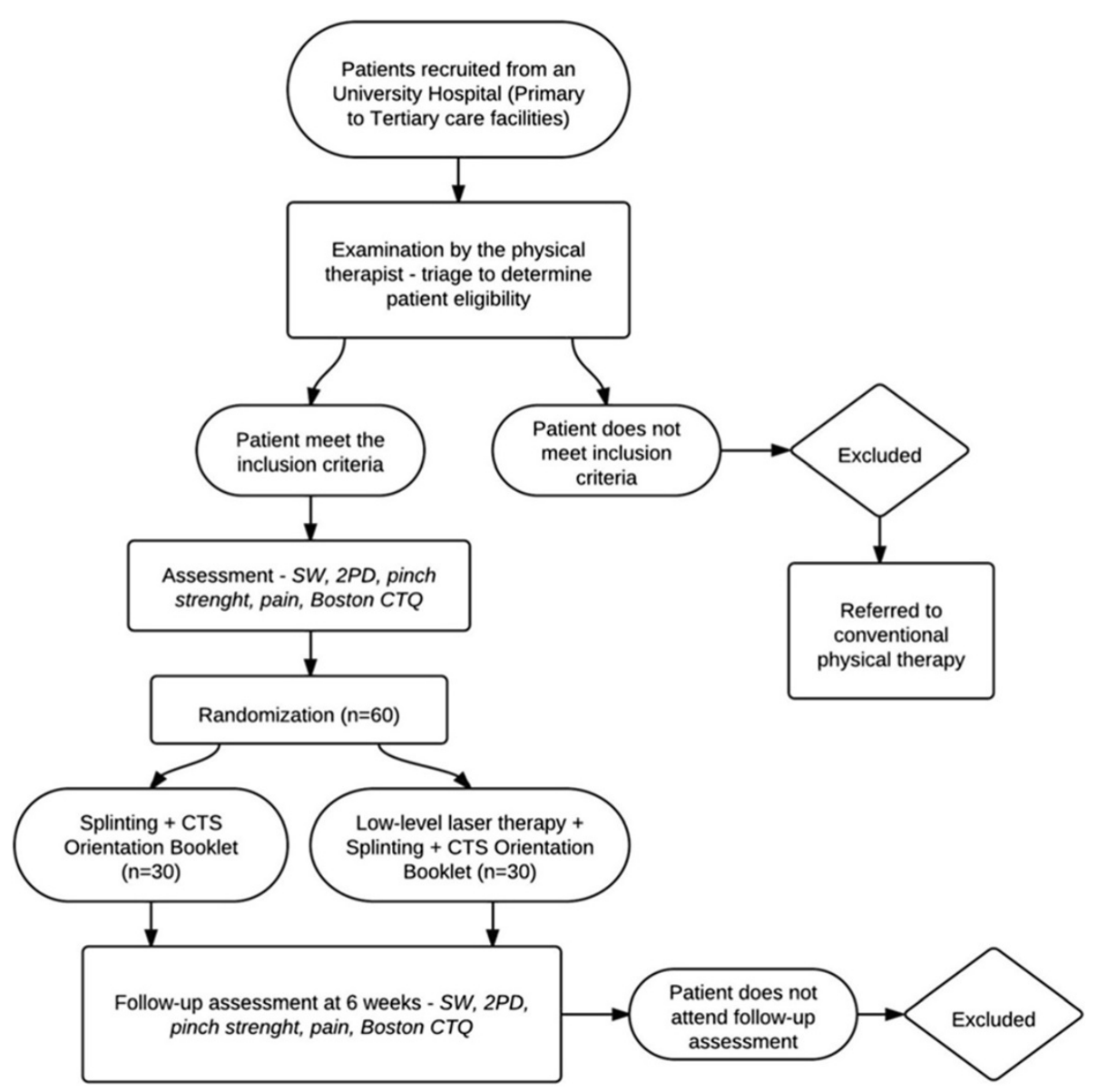

Figure 1 Carpal tunnel syndrome treatment flowchart.

- Low-level laser intervention group. Conservative treatment with night splinting, patient education and low-level laser therapy for 6 weeks (12 therapy sessions).

Hand surgeons will conduct clinical diagnosis and an experienced hand therapist will assess the outcomes, whose will be blinded to group assignment.

\section{Outcome measures}

Assessment will be conducted pre and post intervention based on items related to pain, sensibility, functionality, symptoms and pinch muscle strength. Pain will be assessed by the pain visual analogic scale, sensibility by Semmes Weinstein monofilaments (Sorri ${ }^{\mathrm{TM}}$, Bauru, Brazil) to detect threshold cutaneous sensibility and gnosis tactile through 2PD (North Coast, USA). Isometric pinch strength will be assessed through a dynamometer, Pinch Gauge ${ }^{\text {TM }}$ (North Coast, USA). BCTQ [6] will be used as a specify disease functional and symptom related self-reported measure.

\section{Interventions}

An experienced hand therapist will perform all interventions, in Rehabilitation Center of Clinical Hospital of the Medical School of Ribeirão Preto, University of São Paulo, Brazil.

\section{Home orientations}

Patient education booklet A patient education booklet will be written specially for this study. It contains home and work orientation with emphasis in preventing activities which put the wrist in risk of median nerve compression at carpal tunnel, like excessive flexion and repetitive movement with the fingers or prolonged isometric sustained grip.

\section{Wrist orthoses}

The prescribed orthoses design will be in neutral wrist position, called immobilization splint, type 0 , with the aim to reduce carpal intratunnel pressure and prevent from flexion posture (Figure 2), during night for 6 weeks. 


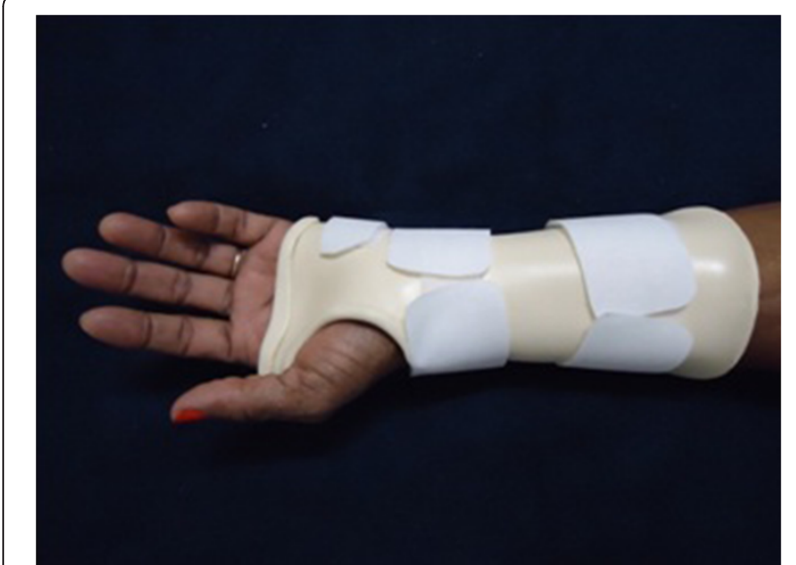

Figure 2 Wrist neutral immobilization splint, type 0.

\section{Low-level laser therapy}

A gallium-indium-phosphorus-aluminum (AlGaInP) laser emitter - Laserpulse ${ }^{\mathrm{TM}}$, will be used (Ibramed $^{\mathrm{TM}}$, Amparo, Brazil), with the following parameters: with wavelength $660 \mathrm{~nm}$, mean power $30 \mathrm{~mW}$, continuous regime and area of bean of $0,06 \mathrm{~cm}^{2}$. The laser irradiation will be done with fluency of $10 \mathrm{~J} / \mathrm{cm}^{2}$, energy (E) of $0.6 \mathrm{~J}$, and exposure time of 20 s for point, totaling six points of irradiation over the carpal tunnel. The laser will be positioned at an angle of $90^{\circ}$ to the skin, according to the contact point technique. The patients will be irradiating twice a week, for 6 weeks (12 therapy sessions).

Gauging the laser emission will be conducted initially and after completion of the experiments.

\section{Statistical analysis \\ Data-analysis}

A linear mixed-effects model will be used to compare the results. This model assumes individuals as random effects and groups as fixed effects, using time variation and interaction between them for calculating mean, standard deviation, and coefficient of variation. A $95 \%$ confidence interval and 5\% significance level will be adopted. Linear mixed-effect models (random and fixed effects) are typically used for the analysis of grouped data from the same individual when independence supposition between observations within the group is not adequate.

This model assumes that the residual value from the difference between the predicted and observed values has a normal distribution, with zero mean and constant variance. In those situations where this supposition was not observed, the variable response was converted. The model was adjusted with SAS version 9.0 software.

\section{Discussion}

Despite the widespread use of LLLT as one of the most popular and commonly used modalities in the field of physiotherapy, there is still limited evidence of its effectiveness. Only a few RCTs have investigated the effect of LLLT in treating patients with CTS; often with varying methodology qualities and have not been able to provide evidence regarding its usefulness.

The advantages of this study would be comparing the LLLT for patients with CTS, associated or not with other modalities like wrist orthoses and a patient education booklet to provide some evidence regarding this indication and use.

\section{Abbreviations}

CTS: Carpal Tunnel Syndrome; BCTQ: Boston Carpal Tunnel Questionnaire; 2PD: Two point discrimination; LLLT: Low level laser therapy;

EMG: Electroneuromyography; AsGalP: Gallium- indium-phosphorus-arsenide; $\mathrm{RCT}$ : Randomised clinical trials.

\section{Competing interests}

The authors declare that they have no competing interests.

\section{Authors' contribution}

The primary authors for this protocol are RIB, EKSR \& GT. RRJG, AMM and MCRF wrote the manuscript. RIB \& MCRF created the protocol. VMCE \& RRJG directed the publication. NM \& MCRF did the methodological quality assessment. All the authors read and approved the final manuscript.

\section{Acknowledgements}

The study is funded by São Paulo Research Foundation - FAPESP and Fundação de Apoio ao Ensino, Pesquisa e Assistência of Clinics Hospital, Faculty of Medicine of Ribeirão Preto, University of São Paulo - FAEPA and is conducted by the University of São Paulo, located in Ribeirão Preto, São Paulo, Brazil.

\section{Author details}

${ }^{1}$ Rehabilitation and Functional Performance Program, Faculty of Medicine of Ribeirão Preto, University of São Paulo, Avenida Bandeirantes, 3900, Ribeirão Preto, SP CEP 14049-900, Brasil. ²Department of Neurology, Psychiatry and Medical Psychology, Faculty of Medicine of Ribeirão Preto, University of São Paulo, Avenida Bandeirantes, 3900, Ribeirão Preto, SP CEP 14049-900, Brazil. ${ }^{3}$ Department of Biomechanics, Medicine and Rehabilitation of the Locomotor Apparatus, Faculty of Medicine of Ribeirão Preto, University of São Paulo, Avenida Bandeirantes, 3900, Ribeirão Preto, SP CEP 14049-900, Brazil.

Received: 6 November 2012 Accepted: 6 December 2012

Published: 13 December 2012

\section{References}

1. Luchetti R: Etiopathogenesis. In Carpal tunnel syndrome. 1st edition. Edited by Luchetti R, Amadio P. Rome: Springer; 2007:4-27.

2. Atroshi I, Gummerson C, Ornstein E, Johnsson R, Ranstam J: Carpal tunnel syndrome and keyboard use at work: a population based study. Arthritis Rheum 2007, 56:620-625.

3. Madura T: Pathophysiologic of peripheral nerve injury. In Basic principles of peripheral nerve disorders. Edited by SeyedMansoorRayegani. Croatia: Intech; 2012:01-16.

4. Ceruso M, Angeloni R, Lauri G, Checcucci G: Clinical diagnosis. In Carpal tunnel syndrome. 1st edition. Edited by Luchetti R, Amadio P. Rome: Springer; 2007:64-68.

5. Chang CW, Wang YC, Chang KF: A practical electrophysiological guide for non-surgical and surgical treatment of carpal tunnel syndrome. J Hand Surg (Br) 2008, 33(1):32-37.

6. Levine DW, Simmons BP, Koris MJ, Daltroy LH, Hohl GG, Fossel AH, Katz JN, et al: A self administered questionnaire for the assessment of severity of symptoms and functional status in carpal tunnel syndrome. J Bone Joint Surg 1993, 75(11):1585-1592.

7. Orfale AG, Araújo PMP, Ferraz MB, Natour J: Translation into Brazilian Portuguese, cultural adaptation and evaluation of the reliability of the 
Disabilities of the Arm, Shoulder and Hand Questionnaire. Braz J Med Biol Res 2005, 38:293-302.

8. Elui VMC, Fonseca MCR, Mazzer PYCN, Mazzer N, Barbieri CH: Compression syndrome in upper limb. In Hand rehabilitation. Edited by Freitas PP. São Paulo: Atheneu; 2005:275-299.

9. Bell-Krotoski J: Sensibility testing: history, instrumentation and clinical procedures. In Rehabilitation of the hand and upper extremity. Volume 1. 6th edition. Edited by Pepper D, Gunzel L. Philadelphia: Elsevier Mosby; 2011:132-151.

10. Rosén B, Lundborg G: A model instrument for the documentation of outcomes nerve repair. J HandSurg [Am] 2000, 25(3):535-543.

11. Rosental TL, Beredjiklian PK, Guyette TM, Wieland AJ: Intra and interobserver reliability of sensibility testing asymptomatic individuals. Ann Plast Surg 2000, 44:605-609.

12. Novak CB: Evaluation of hand sensibility: a review. J Hand Ther 2001, 14(4):266-272.

13. Byl N, Lean J, Cheney LK: TheByl- cheney-Boczai sensory discriminator: reliability, validity and responsiveness for testing sterognosis. $\int$ Hand Ther 2002, 15(4):315-330.

14. Giannini F: Quantitative assessment of historical and objective findings: a New clinical severity scale of CTS. In Carpal tunnel syndrome. 1st edition. Edited by Luchetti R, Amadio P. Rome: Springer; 2007:82-88.

15. Geere J, Chester R, Kale S, Jerosch-Herold C: Power grip, pinch grip, manual muscle testing or thenar atrophy - which should be assessed as a motor outcome after carpal tunnel decompression? A systematic review. BMC Musculoskelet Disord 2007, 8:114.

16. Padua L, Padua R, Moretti C, Nazzaro M, Tonali P: Clinical outcome and Neurophysiological results of Low-power laser irradiation in carpal tunnel syndrome. Lasers Med Sci 1999, 14:196-202.

17. Muller M, Tsui D, Schnurr R, Hard J, Macdermid JC: Effectives of hand therapy interventions in primary management of carpal tunnel syndrome: a systematic review. J HandTher 2004, 17(2):210-228.

18. Krischak A, Krasteva F, Schneider D, Gulkin F, Gebhard M: Physiotherapy after Volar plating of wrist fractures is effective using a home exercise program. Archives of Physical Medicine and Rehabilitation 2009, 90(4):537-544

19. Evans RB: Therapist's Management of carpal tunnel syndrome: a Pratical approach. In Rehabilitation of the hand and upper extremity. Volume 1. 6th edition. Edited by Pepper D, Gunzel L. Philadelphia: Elsevier Mosby; 2011:666-678.

20. Basford JR, Hallman HO, Matsomoto JY, Moyer SK, Buss JM, Baxter GD: Effects of $830 \mathrm{~nm}$ continuous wave laser diode irradiation on median nerve function in normal subjects. Lasers Surg Med 1993, 13:597-604.

21. Gigo-Benato D, Geuna S, Rodrigues AC, Tos P, Fornaro M, Boux E, Battiston B, Giacobini-Robecchi MG: Low-power laser Biostimulationenhances nerve repair after end-to-side neurorrhaphy: a double-blind randomized study in the rat median nerve model. Lasers Med Sci 2005, 19:57-65.

22. Gigo-Benato D, Geuna S, Rochkind S: Phototherapy for enhancing peripheral nerve repair: a review of the literature. Muscle Nerve 2005, 31:609-701.

23. Anders JJ, Geuna S, Rochkind S: Phototherapy promotes regeneration and functional recovery of injured peripheral nerve. Neurol Res 2004, 26:233-239.

24. Chen YS, Hsu SF, Chiu CW, Lin JG, Chen CT, Yao CT: Effects of Low-power pulsed laser on peripheral nerve regeneration in rats. Microsurgery 2005, 25:83-89.

25. Ozen T, Orhan K, Gorur I, Ozturk A: Efficacy of Low level laser therapy on neurosensory recovery after injury to the inferior alveolar nerve. Head\& Face Medicine 2006, 2:3.

26. Reis FA, Belchior ACG, Carvalho PTC, Silva BAK, Pereira DM, Silva IS, Nicolau RA: Effects of laser therapy $(660 \mathrm{~nm})$ on recovery of the sciatic nerve in rats after injury through Neurotmesis followed by Epineural anastomosis. Lasers Med Sci 2009, 24(5):741-747.
27. Barbosa RI, Marcolino AM, Guirro RRJ, Mazzer N, Barbieri CH, Fonseca MCR: Comparative effects of wavelengths of low-power laser in regeneration of sciatic nerve in rats following crushing lesion. Lasers Med Sci 2010, 25:423-430.

28. Marcolino AM, Barbosa Rl, Fonseca MCR, Mazzer N: Low intensity laser (830 NM) functional to recover of the sciatic nerve in rats. Acto OrtopédicaBrasileira 2010, 18:207-211.

doi:10.1186/1471-2474-13-248

Cite this article as: Barbosa et al.: Effectiveness of low-level laser therapy for patients with carpal tunnel syndrome: design of a randomized single-blinded controlled trial. BMC Musculoskeletal Disorders 2012 13:248.

\section{Submit your next manuscript to BioMed Central and take full advantage of:}

- Convenient online submission

- Thorough peer review

- No space constraints or color figure charges

- Immediate publication on acceptance

- Inclusion in PubMed, CAS, Scopus and Google Scholar

- Research which is freely available for redistribution

Submit your manuscript at www.biomedcentral.com/submit
() Biomed Central 